\title{
LAS FERIAS GANADERAS EN CANTABRIA: DE TRADICIÓN CULTURAL ARRAIGADA A ELEMENTO PATRIMONIAL Y ATRACTIVO TURÍSTICO
}

\author{
Carmen GIL DE ARRIBA \\ Universidad de Cantabria
}

Recibido: 24/10/2011

Devuelto: $29 / 05 / 2012$

Aceptado: 18/06/2012

RESUMEN: Las exhibiciones tradicionales de reses y las ferias ganaderas mantienen, hoy en día, un peso notable en las áreas rurales de la Comunidad Autónoma de Cantabria. Este tipo de manifestaciones se hallan cada vez más relacionadas con actividades recreativas y de ocio, siendo capaces de atraer un número creciente de visitantes no directamente vinculados con el ámbito pecuario. Además de este novedoso atractivo turístico, el resurgir de estas prácticas rurales pone de manifiesto la aparición de un proceso de revalorización y de patrimonialización que deben ser entendidos dentro de un marco de análisis más amplio. Es conforme a estas circunstancias que las ferias tradicionales de ganado están contribuyendo en la actualidad al desarrollo de actividades turísticas y de ocio en varias zonas rurales de Cantabria. En este artículo estudiamos el contexto social e histórico, desde finales del siglo XIX y, a partir de varios estudios de caso, planteamos algunas hipótesis interpretativas de la situación actual y de los posibles escenarios de evolución futura.

PALABRAS CLAVE: ferias tradicionales de ganado, patrimonio cultural inmaterial, procesos de patrimonialización, turismo cultural, espacio rural, Cantabria.

TRADITIONAL CATTLE FAIRS IN CANTABRIA (SPAIN): FROM A DEEPROOTED CULTURAL TRADITION TO A HERITAGE ELEMENT AND A TOURIST ATTRACTION

ABSTRACT: Traditional cattle fairs and exhibitions are still important in the rural areas of the Autonomous Community of Cantabria (Northern Spain). However, they are increasingly linked with recreational and leisure activities and so can attract a broader spectrum of visitors. In addition, the resurgence of these old rural practices reflects a patrimonialization process that must be understood in the wider framework of globalization. It is in this context that traditional cattle fairs are contributing to the development of tourism and leisure activities in rural areas. In this article we analyse some cases of study, in a historical perspective, from the end of 19th century to the present.

KEY WORDS: traditional cattle fairs, intangible cultural heritage, patrimonialization, cultural tourism, rural areas, Cantabria, Spain. 


\section{INTRODUCCIÓN: BASES PARA EL ANÁLISIS E INTERPRETACIÓN DE UNAS PECULIARES ACTIVIDADES DE OCIO EN LOS ENTORNOS RURALES DE CANTABRIA}

Este artículo tiene como principal objetivo estudiar el incremento del atractivo turístico y recreativo alcanzado por las ferias ganaderas y celebraciones tradicionales, sobre todo centradas en el ganado bovino, que se llevan a cabo actualmente en las zonas rurales de Cantabria. Este objetivo de análisis parte de una comprobación básica como es la tendencia al aumento del número de manifestaciones de este tipo, así como del de visitantes y espectadores que acuden a las mismas sin tener relación directa con la actividad pecuaria y en su mayor parte procedentes de ámbitos urbanos. Así, mientras la ganadería pierde peso como sector productivo, las ferias de ganado tradicionales adquieren otras orientaciones nuevas, entre las que las de carácter lúdico-festivo aparecen como más evidentes, si bien, como veremos más adelante, también son comprobables otro tipo de finalidades como las ideológicas e identitarias.

Además, el moderno resurgir de este tipo de prácticas vernáculas, propias de sociedades rurales, implica su puesta en valor y su construcción social como componente patrimonial. En este sentido, más allá del mero punto de vista local, el trasfondo interpretativo se plantea en relación con los actuales procesos de globalización y de terciarización y más en particular, con la gradual funcionalidad turística y recreativa atribuida a los espacios rurales.

En cuanto a su estructura, el trabajo se inicia con una reflexión general sobre lo que se entiende por proceso de patrimonialización y sobre el marco institucional en el que se desenvuelven hoy en día los espacios rurales de Cantabria. Igualmente, se analiza el contexto histórico, desde finales del siglo XIX hasta la actualidad, de interrelación entre ferias ganaderas y actividades de ocio en la región; para centrarse a continuación en varios estudios de caso particulares, prestando especial interés a las denominadas ferias de año y al abundante ciclo de celebraciones coincidentes con los meses de otoño. Asimismo, se tienen en cuenta algunos proyectos recientes de museificación de este tipo de eventos y tradiciones ganaderas. Finalmente, este esquema de trabajo permite desarrollar algunos criterios interpretativos de la situación actual y vislumbrar posibles escenarios de evolución de cara al futuro.

\section{LA PUESTA EN VALOR PATRIMONIAL DE LAS FERIAS GANADERAS EN EL CONTEXTO SOCIOECONÓMICO ACTUAL.}

La histórica orientación ganadera de la Comunidad Autónoma de Canta- 
bria y la fuerte especialización de su sector primario en la producción de ganado vacuno, tanto de leche como de carne, constatadas desde al menos mediados del siglo XIX (LANZA, 2001), proporcionan las primeras pistas para comprender e interpretar la notoriedad que las ferias ganaderas tradicionales siguen teniendo en la actualidad en bastantes municipios de la región ${ }^{1}$.

Más en concreto, durante las últimas décadas, lejos de sufrir un retroceso similar al de las propias actividades ganaderas, por el contrario, este tipo de manifestaciones festivas periódicas han venido experimentando un resurgir indudable, promovido desde el punto de vista institucional y organizativo por ayuntamientos, juntas vecinales y sobremanera por el Gobierno Regional a través de la actual Consejería de Ganadería, Pesca y Desarrollo Rural, con distintas primas o incentivos a los propietarios por cada cabeza de ganado participante en las concentraciones, así como a partir del impulso de diversas asociaciones y cooperativas de ganaderos ${ }^{2}$.

De forma un tanto paradójica frente a las problemáticas a las que debe hacer frente el sector agropecuario, esta clase de eventos festivos repetidos e incrementados anualmente son capaces de atraer a un público que va en aumento y que acude, en su mayoría, para participar en la feria o en la exposición, no ya como ganaderos o tratantes, sino con un carácter cada vez más lúdico como visitantes procedentes de diferentes puntos de la región, a veces considerablemente distantes del lugar de concentración y sobre todo desde zonas urbanas como Santander o Torrelavega. Asimismo, en los últimos años también se observa la presencia creciente de turistas y excursionistas venidos de otras provincias limítrofes, para los cuales esta clase de acontecimientos resultan una oferta de ocio original y complementaria a realizar durante su estancia en Cantabria.

Todo ello revela además un incipiente proceso de patrimonialización de este tipo de prácticas, originariamente características de sociedades rurales, en el que hoy en día, además de las instituciones públicas, intervienen diversos actores sociales, algunos de ellos relativamente ajenos al medio rural. De hecho, como veremos, este fenómeno de apropiación patrimonial, en tanto que construcción social distintiva que legitima determinadas concepciones y valoraciones, se sitúa dentro de un contexto más amplio de búsqueda de símbolos y señas de identidad regionales con una notable base territorial.

\footnotetext{
${ }^{1}$ Ya el escritor costumbrista José María de Pereda, en la narración titulada "El 4 de octubre" agregada en la edición de 1877 de las Escenas Montañesas se refiere a esta tradición.

${ }^{2}$ Entre las que pueden citarse: Asaja-Asociación de Jóvenes Agricultores, Asociación de Criadores de Raza Tudanca, Asociación Frisona de Cantabria, Asociación Independiente de Agricultores y Ganaderos de Cantabria, etc.
} 


\section{II.1. El concepto de patrimonio cultural inmaterial y las ferias anuales de ganado.}

A la hora de evaluar este reciente desarrollo del valor patrimonial de las ferias ganaderas que siguen repitiéndose en bastantes municipios de Cantabria debemos tener en cuenta, en primer lugar, la propia consideración establecida por la UNESCO que incluye, dentro del concepto de patrimonio cultural inmaterial, diversas tradiciones activas como es el caso de rituales, costumbres, usos sociales y actos festivos, capaces de estructurar la vida de comunidades y grupos al ser compartidos y valorados por buena parte de sus miembros.

Según esta organización de Naciones Unidas, la importancia genérica de toda celebración que pueda interpretarse como patrimonio cultural inmaterial reside en la disposición de la misma para afirmar la identidad de quienes las practican en tanto que comunidad o grupo social, estando además fuertemente asociadas con acontecimientos representativos que perduran en la memoria colectiva, como los cambios cíclicos de estación o los distintos períodos de las tareas agrarias. Asimismo, las expresiones de este tipo de prácticas pueden ser tanto pequeñas reuniones como celebraciones de grandes proporciones. De una manera u otra, lo que en todos los casos resulta evidente es que dichas conmemoraciones suelen efectuarse en lugares y momentos especiales o significativos; así en el ejemplo que nos ocupa, las ferias de ganado tradicionales acostumbran a celebrarse en plazas, praderías, brañas, cajiga$\mathrm{les}^{3}$, fincas, seles ${ }^{4}$ o distintos espacios acondicionados como tales recintos fe-

3 En Cantabria, un "cajigal" (a veces escrito "cagigal") es un terreno poblado de "cajigas" (a veces también puede aparecer como "cagigas"), roble común, Quercus robur, árbol típicamente atlántico. Se trata por lo general de árboles robustos y de gran porte, que pueden alcanzar una considerable altura, con un tronco muy grueso, sobre todo en el caso de ejemplares aislados. En Cantabria están inventariados algunos individuos singulares como la Cajiga de Abiada en la Hermandad de Campoo de Suso. La Real Academia Española considera el término "cajiga", en femenino, sinónimo de "quejigo". Este tipo de robledal es propio de terrenos fértiles, por lo que históricamente se han visto desplazados por los prados, quedando no obstante algunos ejemplares aislados.

${ }^{4}$ El término "sel" designa una forma histórica de organización del espacio ganadero a lo largo de toda la vertiente cantábrica, tanto en zonas de Cantabria como de Asturias, País Vasco y Navarra. Se trata de porciones de terreno de propiedad comunal, delimitadas a menudo por mojones y con unas características de uso especiales, propias de una economía de tipo pastoril, basada en la explotación de montes, pastos y terrenos comunales. El diccionario de la Real Academia Española lo define como "pradería en la que suele sestear el ganado vacuno" y establece el origen prerromano del vocablo. Algunos autores lo consideran sinónimo de "majada". Tradicionalmente se habla de "seles de verano" y de "seles de invierno" o "invernizos", lo que pone de manifiesto la existencia de prácticas de trashumancia. 
riales, coincidiendo con la llegada de la primavera o del otoño, el final de las cosechas, una festividad religiosa, etc.

No obstante, como también reconoce la UNESCO, en las sociedades modernas, todo este tipo de acontecimientos festivos herencia del pasado se ven intensamente afectados por los cambios experimentados por las comunidades tradicionales y por la evolución del contexto socioeconómico en general. Así, en ocasiones se origina el desinterés de las propias poblaciones por estas prácticas comunitarias, lo que conduce a su abandono o desaparición gradual, mientras que otras veces por contra se produce una participación creciente de turistas y de personas externas a la comunidad, en un proceso evidente de mercantilización. Esta segunda característica, es decir la intervención progresiva de agentes externos y la orientación hacia prácticas de ocio con finalidad lucrativa, puede constatarse en el caso que nos ocupa. Estas circunstancias, además de representar un proceso de transformación de las ferias ganaderas desde sus precedentes más ancestrales a las expresiones actuales, conlleva también implicaciones económicas, sociopolíticas e ideológicas que explican, en buena medida, el éxito y la proliferación de dichas manifestaciones.

\section{II.2. El medio rural de Cantabria, desarrollo sostenible y turismo: marco institucional del fenómeno de apropiación patrimonial de las ferias ganaderas.}

Para entender el contexto institucional, tanto estatal como autonómico, en el que se lleva a cabo este paulatino proceso de valoración patrimonial de las ferias ganaderas de Cantabria es necesario hacer referencia, por un lado, a la Ley 45/2007 de 13 de diciembre para el desarrollo sostenible del medio rural español y por otro, al Decreto 30/2010 de 22 de abril por el que se regula la ejecución de los programas de desarrollo rural sostenible en la Comunidad Autónoma. Ambos textos legales son la demostración de cómo hoy en día la política rural se concibe cada vez más como una política transversal, con objetivos económicos, sociales y ambientales, sin limitarse al antiguo enfoque exclusivamente agrario. De aquí la pretensión presente en ambas normativas de instaurar una nueva política rural, tratando de integrar las actuaciones de las distintas Administraciones públicas y del sector privado, con el fin de lograr que los habitantes de estas áreas mejoren su situación socioeconómica y tengan acceso a unos servicios suficientes y de calidad, al tiempo que se protege y conserva su patrimonio natural y cultural.

En el caso concreto de Cantabria, siguiendo estos planteamientos generales y en función de las competencias autonómicas para la delimitación y calificación de zonas rurales (art. 10 de la mencionada Ley 45/2007), el Decreto 
Mapa 1. Zonas rurales de Cantabria.

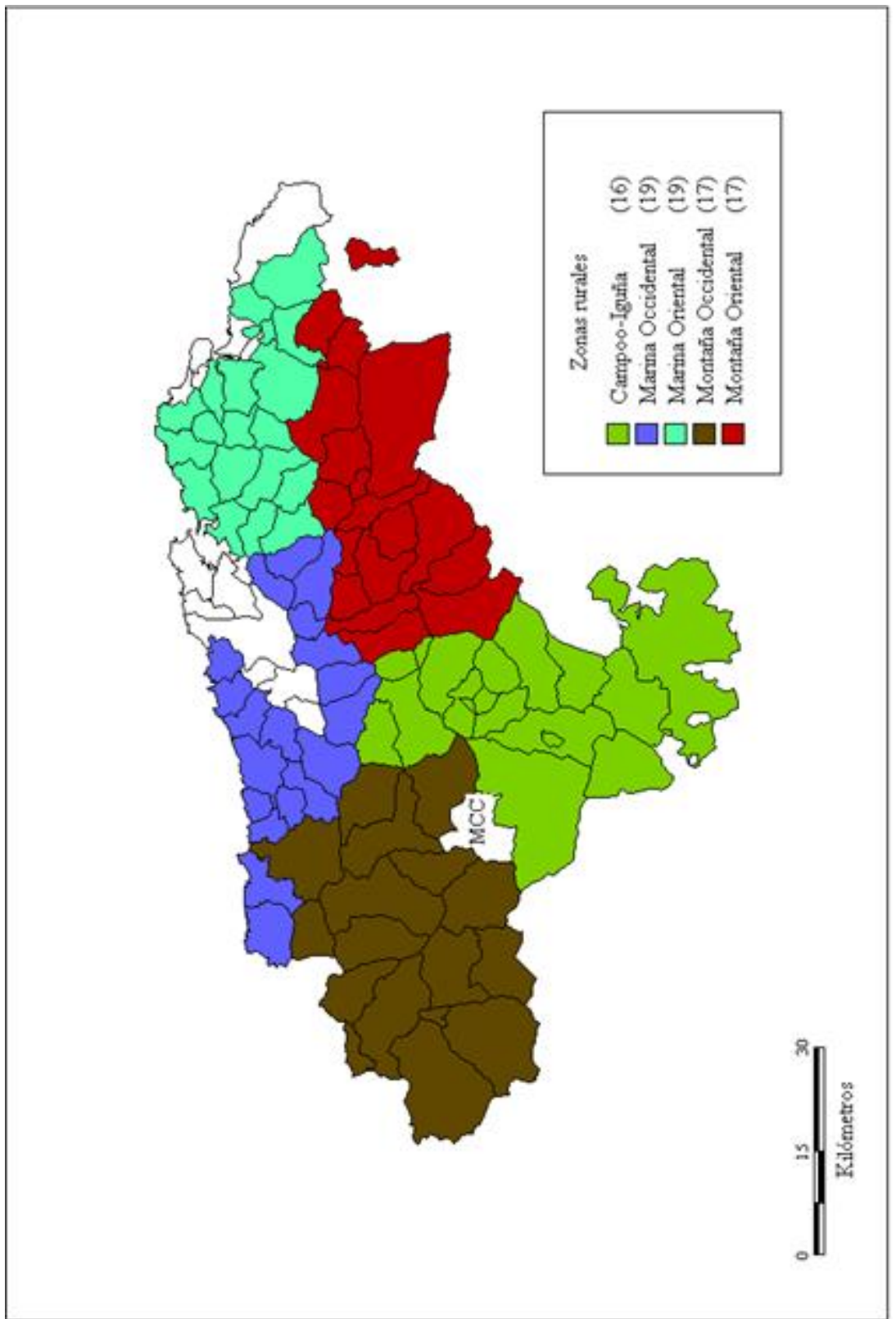

FuENTE: Decreto 30/2010 de 22 de abril, Consejo de Gobierno, BOC de 4 mayo de 2010. Elaboración propia. MCC: Mancomunidad Campoo-Cabuérniga. (Entre paréntesis el número de municipios por comarca). 
Mapa 2. Comarcas agrarias de Cantabria.

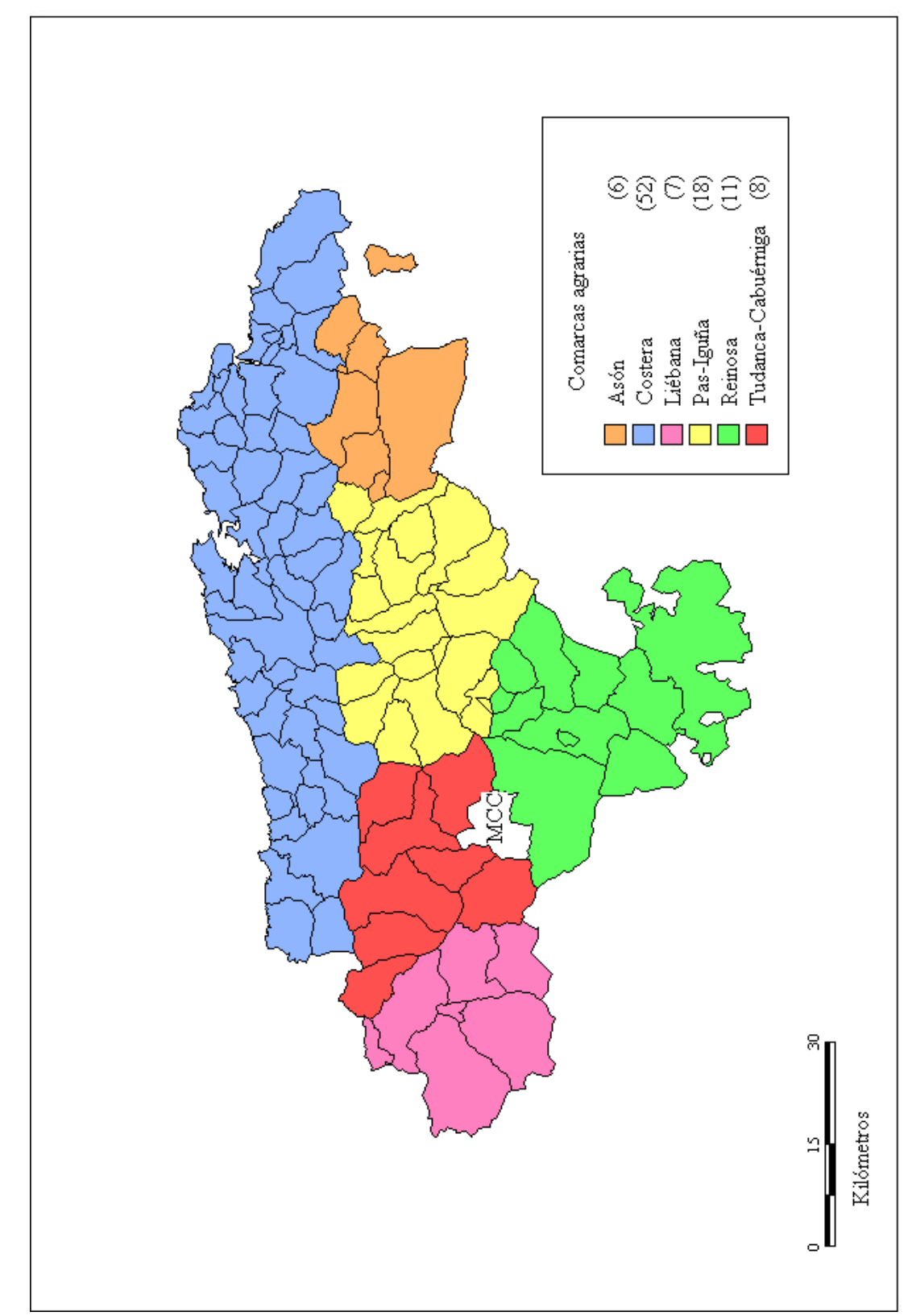

FUENTE: Ministerio de Agricultura, Pesca y Alimentación (1978) e ICANE, Consejería de Ganadería, Agricultura y Pesca. Gobierno de Cantabria y Censos agrarios, INE. Elaboración propia. (Entre paréntesis el número de municipios por comarca), (MCC: Mancomunidad Campoo-Cabuérniga). 
Mapa 3. Mapa comarcal ganadero de Cantabria 2009.

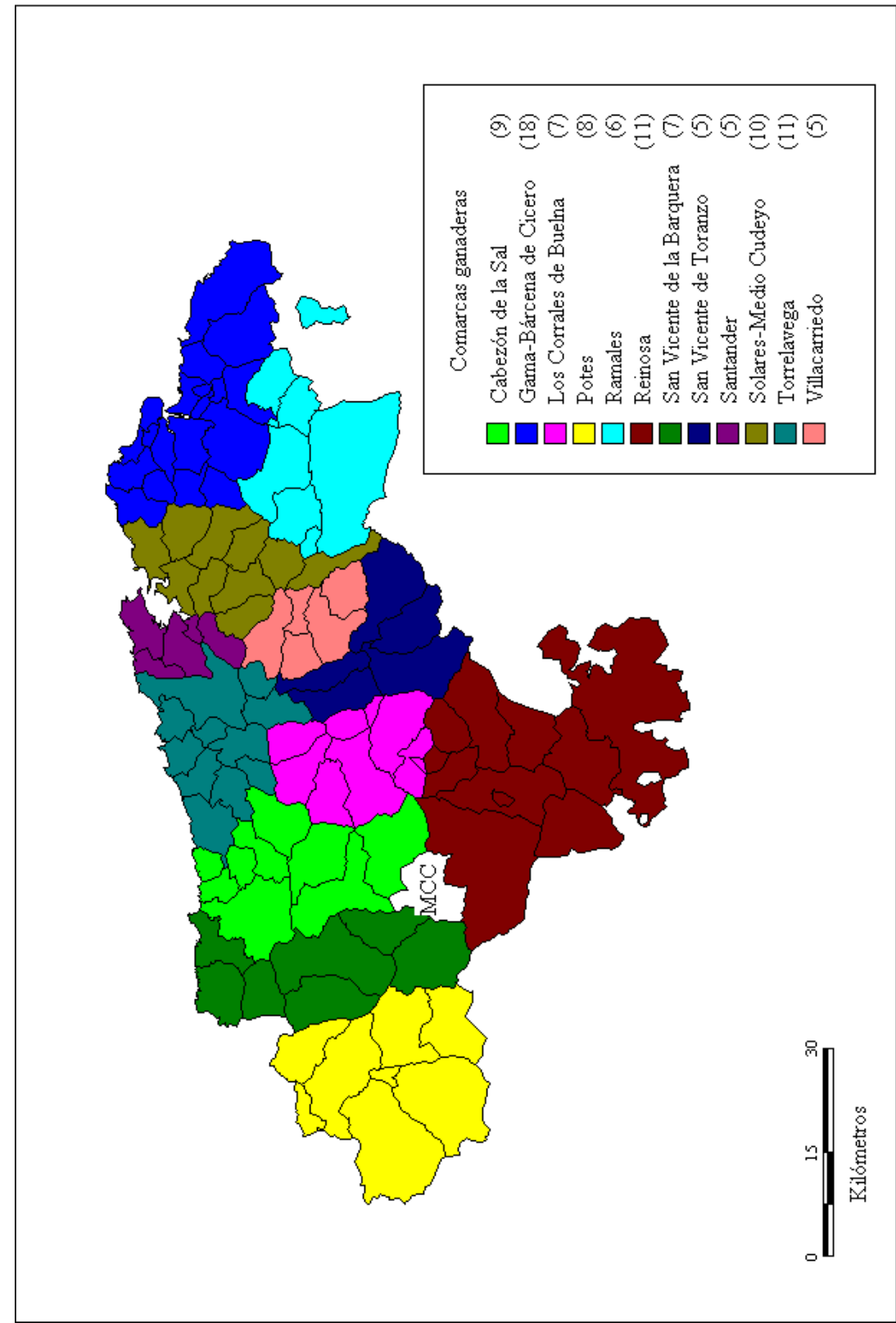

FUENTE: Mapa Comarcal Ganadero de España. Ministerio de Agricultura, Alimentación y Medio Ambiente. Elaboración propia. MCC: Mancomunidad Campoo-Cabuérniga. (Entre paréntesis el número de municipios por comarca). 
30/2010 establece que su medio rural está integrado por un total de 88 municipios de los 102 que componen la región ${ }^{5}$ (véase el MAPA 1). Dicho total se divide en cinco zonas, tres de ellas de interior: la Montaña Occidental, Campoo-Iguña, la Montaña Oriental, la Marina Occidental y la Marina Oriental. A su vez, conforme a la Ley estatal, las tres primeras se califican como "zonas a revitalizar", mientras que las dos marinas aparecen consideradas como "zonas rurales periurbanas".

Esta clasificación territorial difiere de la habitualmente utilizada en los Censos agrarios, que distribuye el total de municipios de Cantabria en seis comarcas, sin tener en cuenta el carácter rural o urbano de las mismas (MAPA 2) ${ }^{6}$, y también es distinta de la división geográfica utilizada por el Ministerio de Medio Ambiente y Medio Rural y Marino para la elaboración del mapa comarcal ganadero, que llega a determinar hasta doce comarcas ganaderas en la región, relacionadas con los requisitos y condicionantes de la producción pecuaria (obsérvese el MAPA 3).

Pero más que las diversas clasificaciones comarcales de los espacios rurales y de las actividades ganaderas de Cantabria, resulta interesante, en relación con este fenómeno de apropiación patrimonial de elementos pertenecientes a la cultura rural como son las ferias de ganado, detenerse en los principios básicos y las directrices que el Decreto autonómico 30/2010 instaura retomando los contenidos de la Ley estatal con respecto a las estrategias de ordenación rural y a los planes y actuaciones a llevar a cabo (art. 6 y anexo III). Destacan así dos postulados que indican una valoración del patrimonio en función del avance de determinados sectores como son el turismo y los servicios: el de "impulsar la conservación, promoción y puesta en valor del patrimonio natural y cultural" y el de "estimular la actividad económica, optimizando los aprovechamientos tradicionales e impulsando la innovación y la diversificación productiva" (cap. III, art. 6).

En este mismo contexto general de globalización y terciarización pueden interpretarse las directrices estratégicas recogidas en el anexo III del Decreto $30 / 2010$, entre las que se encuentran la de "ampliar la base económica del medio rural, mediante la preservación de actividades competitivas y multifuncionales y la diversificación de su economía con la incorporación de nue-

\footnotetext{
${ }^{5}$ La Ley de ámbito estatal de 2007 fija en su art. 3 que el medio rural es "el espacio geográfico formado por la agregación de municipios o entidades locales menores definido por las administraciones competentes que posean una población inferior a 30.000 habitantes y una densidad inferior a los 100 habitantes por $\mathrm{km}^{2}$ ".

${ }^{6} \mathrm{Si}$ bien diferenciando claramente la comarca costera de las otras cinco comarcas, todas estas últimas de interior.
} 
vas actividades compatibles con un desarrollo sostenible", destacándose a continuación las actividades turísticas y de educación medioambiental y la de "recuperar, preservar y conservar el patrimonio en sus aspectos natural y cultural y ponerlo en valor como recurso socioeconómico fundamental del medio rural a través de actuaciones públicas y privadas que permitan su utilización compatible con un desarrollo sostenible".

Más en particular, en relación con el apoyo a la actividad agraria (eje 1, actividades económicas y empleo) se trata de "fomentar actuaciones dirigidas a mejorar la valoración social y la estima de las actividades agropecuarias tanto por parte de la sociedad urbana como, sobre todo, por parte de los propios ganaderos y agricultores, resaltando su importante función económica y medioambiental para el conjunto de la sociedad de los territorios, urbanos y rurales". Igualmente dentro del mismo eje temático se pretende "apoyar la dinamización turística que permita avanzar en la puesta en valor de los recursos turísticos locales con enfoque de zona, con particular atención al patrimonio natural y cultural, todo ello orientado a un tipo de turismo de calidad, estable y sostenible", lo mismo que "fomentar las actuaciones de la recuperación y de formación en materia de oficios tradicionales y de actividades artesanas características o exclusivas del territorio, constituyentes del patrimonio rural y susceptibles de aplicarse en el futuro en actividades económicas que contribuyan al desarrollo rural". En definitiva y específicamente en materia cultural (eje 3, servicios y bienestar social), se busca: "garantizar la conservación, recuperación y promoción de la cultura rural local, por su papel esencial en el reconocimiento y afirmación de la identidad de cada territorio", lo mismo que "fomentar la oferta cultural que se presente con soluciones innovadoras y de proximidad, que permitan llevar la cultura a cada pueblo y aldea, como pueden ser las que aprovechan las nuevas tecnologías de la información, las actividades itinerantes y dinámicas, los circuitos de eventos culturales o la localización de espacios culturales de naturaleza policéntrica", así como "incentivar la conservación del patrimonio cultural, tanto arquitectónico (...) como etnográfico" y "favorecer el asociacionismo, la animación socio-cultural, y en general los cauces de participación de la sociedad rural en las cuestiones que les afectan".

Al hilo de todo lo anterior, las ferias ganaderas, convertidas cada vez más en un componente patrimonial del medio rural de Cantabria, resultan también un producto turístico distintivo mediante el cual poder integrarse en la economía global.

Pero puesto que este fenómeno de patrimonialización debe ser entendido desde un punto de vista procesual y dinámico, veamos cuáles son los precedentes históricos del mismo. 


\section{LA CANTABRIA GANADERA: LAS INICIALES EXPOSICIO- NES Y CERTÁMENES PROVINCIALES DE GANADO Y SU RELACIÓN CON LAS PRIMERAS ACTIVIDADES DE OCIO.}

En términos generales, la patrimonialización de la cultura y de la naturaleza son dos fenómenos análogos y a menudo simultáneos que han experimentado un fuerte crecimiento en las últimas décadas, en paralelo con los procesos de globalización y terciarización. Ambos fenómenos de puesta en valor patrimonial se inician en el siglo XIX, si bien su consolidación no se produce hasta la segunda mitad del XX, coincidiendo precisamente con el auge de las actividades turísticas y recreativas, para alcanzar una continua aceleración en los últimos años. De este modo, en la actualidad existen bastantes ejemplos de una construcción social sistematizada de elementos patrimoniales, cada vez más demandados por la población para su uso y disfrute.

Centrándonos en los precedentes históricos de nuestro caso concreto de estudio, ya desde finales del siglo XVIII en lo que actualmente constituye la Comunidad Autónoma de Cantabria, se halla documentado (LANZA, 2001) el incremento de las superficies destinadas a prados y pastizales y con esto de la capacidad forrajera, junto con la expansión del cultivo de maíz. Desde temprano, todo ello tuvo como consecuencia un notable desarrollo de la cabaña ganadera, con una paulatina especialización en ganado bovino, particularmente en comarcas de unas condiciones geográficas específicas como la del Valle del Pas, la del Valle de Iguña, la de Tudanca-Cabuérniga o la de Liébana.

A lo largo del siglo XIX y a medida que se va produciendo un aumento de la demanda urbana de leche, se mantiene todavía en la entonces Provincia de Santander el predominio de las razas autóctonas, como el ganado tudanco y las vacas pasiegas, la mayor parte de las veces explotadas con carácter extensivo y plurifuncional (leche, carne y ganado de trabajo). Igualmente, otros subtipos vernáculos también adaptados a las peculiaridades de sus zonas respectivas fueron los de ganado vacuno campurriano y lebaniego.

No obstante, ya en la segunda mitad del siglo XIX, la actividad ganadera en la comarca del Pas empieza a adquirir un carácter marcadamente comercial y exportador, al ocuparse de abastecer de productos lácteos no sólo a la ciudad de Santander, sino también a varias capitales de provincia españolas como Madrid o Zaragoza. Es también por aquel entonces cuando comienzan a aparecer en La Montaña ejemplares de razas extranjeras, destacando sobre todo las vacas holandesas o frisonas ${ }^{7}$ que permitían una mayor producción

\footnotetext{
${ }^{7}$ También llamadas pintas por el colorido alterno de su pelaje, normalmente blanco y ne-
} 
lechera. Al mismo tiempo, de lo que primero había sido casi exclusivamente un sistema extensivo e itinerante de alimentación del ganado vacuno, se va pasando a las iniciales formas de explotación intensiva, en estabulación permanente.

\section{III.1. Ferias ganaderas y prácticas de ocio: una temprana vinculación.}

Una característica no menos destacable desde nuestro punto de vista es que esta introducción y perfeccionamiento de la vaca frisona, que más tarde alcanzaría un puesto principal en la producción ganadera no sólo montañesa sino española en general, coincide además con el inicio de las primeras exposiciones y certámenes de ganado y de productos ganaderos, como los celebrados anualmente durante dos décadas en la ciudad de Santander, en un pabellón construido a tal efecto en los terrenos del Verdoso, en la Alameda segunda o también llamada Alameda de Oviedo y organizados por la Junta de Agricultura, Industria y Comercio de la Provincia de Santander ${ }^{8}$ coincidiendo con la Feria de Santiago, en la semana del 25 de julio ${ }^{9}$ (véase el GRÁFICO 1).

Como precedente de estos certámenes de ganado celebrados en Santander hay que mencionar la Exposición General de Agricultura realizada en Madrid en $1857^{10}$, a la que acudieron varios ejemplares de vacas holandesas que por aquellos años empezaban a introducirse en España, esencialmente en toda el área cantábrica desde Guipúzcoa a La Coruña ${ }^{11}$.

Volviendo a nuestra región, entre los años 1870 y 1885 , se calcula que en dichas exposiciones ganaderas provinciales efectuadas en Santander se presentaron en torno a 3.600 cabezas de bovino y más de mil reses de otras especies animales (CASADO, 1983-84) ${ }^{12}$. De tal modo, a lo largo de estos años

gro.

${ }^{8}$ Instaurada en 1848, (LE BouIL, 1965).

${ }^{9}$ Como ya indicamos en otro trabajo (Gil, 2002: 155), varias fuentes señalan que el comienzo de las ferias de ganado de Santiago en la Alameda de Oviedo de Santander se produjo en 1869. No obstante, según hemos podido comprobar al consultar la prensa local, en el periódico La Voz de Cantabria de 9 de agosto de 1938 se da noticia de una primera muestra de ganado vacuno efectuada en la Alameda primera luego llamada de Jesús de Monasterio en 1852, a la que acudió Francisco de Asís, rey consorte y marido de Isabel II. Un año más tarde, hubo otra muestra ganadera en La Albericia. Posteriormente también se documentan exposiciones de ganado en la Alameda de Oviedo en los años 1874, 1882, 1885, 1900, 1905, 1912, 1915,1917 , etc.

${ }^{10}$ Cuya memoria impresa se encuentra en la Biblioteca Nacional.

${ }^{11}$ Para esta última provincia, en la Biblioteca Nacional se conservan al menos dos memorias de exposiciones celebradas los años 1891 y 1892.

${ }^{12}$ Según ha estudiado este autor, entre 1870 y 1889 cada año sin interrupción, se celebra- 
y coincidiendo con las celebraciones festivas estivales, se dieron a conocer en la ciudad ejemplares seleccionados no sólo de la raza holandesa, sino también de otras razas vacunas de procedencia extranjera, como la normanda, bretona, escocesa, suiza, etc., llegadas al puerto marítimo de la capital.

Gráfico 1. Portada del discurso de apertura de la Exposición de Ganados de la provincia de Santander, 31 de julio de 1873.
Gráfico 2. Exposición provincial de ganados en la Alameda segunda o de Oviedo, julio 1872.
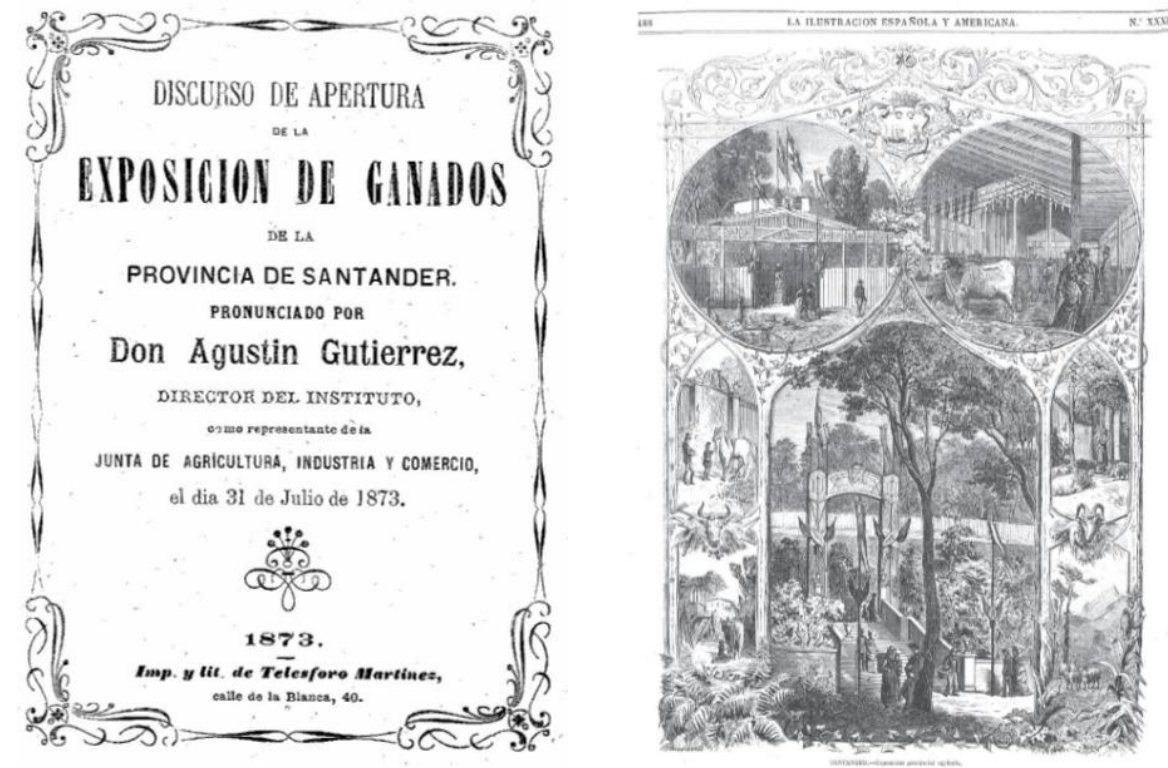

FUENTE: Texto impreso del discurso de inauguración de la Exposición de Ganados de la provincia de Santander, 1873. Santander, Imp. y lit. de Telesforo Martínez. Biblioteca

FUENTE: La Ilustración Española y Americana, año XVI-núm. XXXI, 16 de agosto de 1872 . Nacional.

De esta forma, progresivamente, se fueron produciendo varias mezclas y mestizajes de razas foráneas y de éstas a su vez con las autóctonas. Igual-

ron exposiciones ganaderas en Santander. Posteriormente dicho investigador recoge las de 1895, 1900 y 1911; con esta última, celebrada en un gran pabellón cubierto situado en los terrenos de la fábrica de cervezas La Cruz Blanca, contiguos a la Alameda segunda, en la calle San Fernando, el Consejo Provincial de Fomento de Santander intentó reinstaurar la celebración anual de dichas exposiciones pecuarias en la capital de la provincia, las cuales ya en esta primera década del siglo XX empezaban a languidecer. 
mente, además del ganado, también se exponían distintos productos agrícolas, industriales y comerciales ${ }^{13}$. Todo esto en un ambiente marcadamente festivo y de elevada afluencia de público, no sólo local sino también de fuera de la región, como señala la prensa de estos años.

Con este proceso de expansión pecuaria, la venta de ganado se convierte en una actividad económica destacada (MADARIAGA, 1981) ${ }^{14}$. Igualmente, según fuentes ya citadas (CASADO, 1983-84), entre los años 1865 y 1872 había en la provincia unos treinta y dos mil ganaderos. En este último año, la exposición ganadera anual celebrada en Santander contó con la presencia del rey Amadeo I quien para resaltar la celebración se encargó de distribuir los premios en metálico, las medallas, diplomas y menciones honoríficas ${ }^{15}$. Tal solemnidad motivó la publicación de un interesante material gráfico en la revista La Ilustración Española y Americana ${ }^{16}$-ver GRÁFICO 2-. Años más tarde, la misma revista ilustrada siguió publicando diversos grabados sobre exposiciones posteriores, como las de 1876 y 1882, esta última clausurada por Alfonso XII.

De esta manera, a la promoción naciente de las primeras actividades de ocio en Santander, relacionadas sobre todo con la puesta en valor de sus playas y la aparición de los primeros balnearios marítimos en el Sardinero, vienen a sumarse estas manifestaciones festivas asociadas a la tradición pecuaria y al por entonces espectacular desarrollo de la ganadería regional.

Por otro lado, en el caso de Torrelavega existe constancia documentada de la celebración regular de transacciones ganaderas desde finales del siglo XVIII, con una Real Cédula concedida en 1767 por Carlos III (GUTIÉRREZ, 2003). Ya a mediados del XIX, se celebraban mercados quincenales en los terrenos de La Llama, en los que participaba un número elevado de reses y cuyo ambiente fue recogido en algunas tarjetas postales de la época-véase GRÁFICO 3-. Además, durante las últimas décadas del siglo XIX y primeras del XX, se celebraban anualmente en Torrelavega las llamadas Ferias y Fies-

\footnotetext{
${ }^{13}$ Gervasio González de Linares, hermano mayor de Augusto González de Linares y alcalde del municipio de Cabuérniga entre 1873 y 1877, fue presidente del Consejo de Agricultura, Industria y Comercio de Santander y en 1880 escribió la obra titulada Las exposiciones de ganado en la provincia de Santander. Imp. y lit. de J.M. Martínez.

${ }^{14}$ Benito Madariaga de la Campa señala que entre los años 1889 y 1893, la media anual de ganado vacuno que se vendía en las ferias de Torrelavega se encontraba cercana a las 14.000 reses. Estamos ante el precedente de lo que más tarde sería el Mercado Nacional de Ganados de dicha ciudad.

${ }^{15}$ La presencia en Santander de Amadeo I durante el verano de 1872 también aparece reseñada por Benito Pérez Galdós, en su última serie de Episodios Nacionales: Amadeo I, XXII.

${ }^{16}$ Así, en los números de 1, 8 y de 16 de agosto de 1872.
} 
tas de Santa María, en el mes de abril. De estas celebraciones se conservan algunos programas oficiales ${ }^{17}$ en los que junto con las exposiciones de ganado vacuno y caballar y los premios previstos, aparecen también reseñados distintos festejos como conciertos de música, veladas nocturnas, sesiones de cinematógrafo, funciones de teatro, bailes, etc., a los que se sumaba el conjunto de la población local y algunos visitantes foráneos.

Sin embargo, en la primera década del nuevo siglo, esta clase de certámenes provinciales y locales, similares a los también constatados en otros países y en otras regiones españolas (La Coruña, Zaragoza, León, Valladolid, Valencia,...), comienzan a perder la novedad y el interés general que habían despertado durante el último cuarto del siglo XIX. Así pues, las ferias ganaderas fueron experimentando un estancamiento e incluso una disminución paulatina.

Gráfico 3. Tarjeta postal de comienzos del siglo XX. Feria de ganado en Torrelavega.

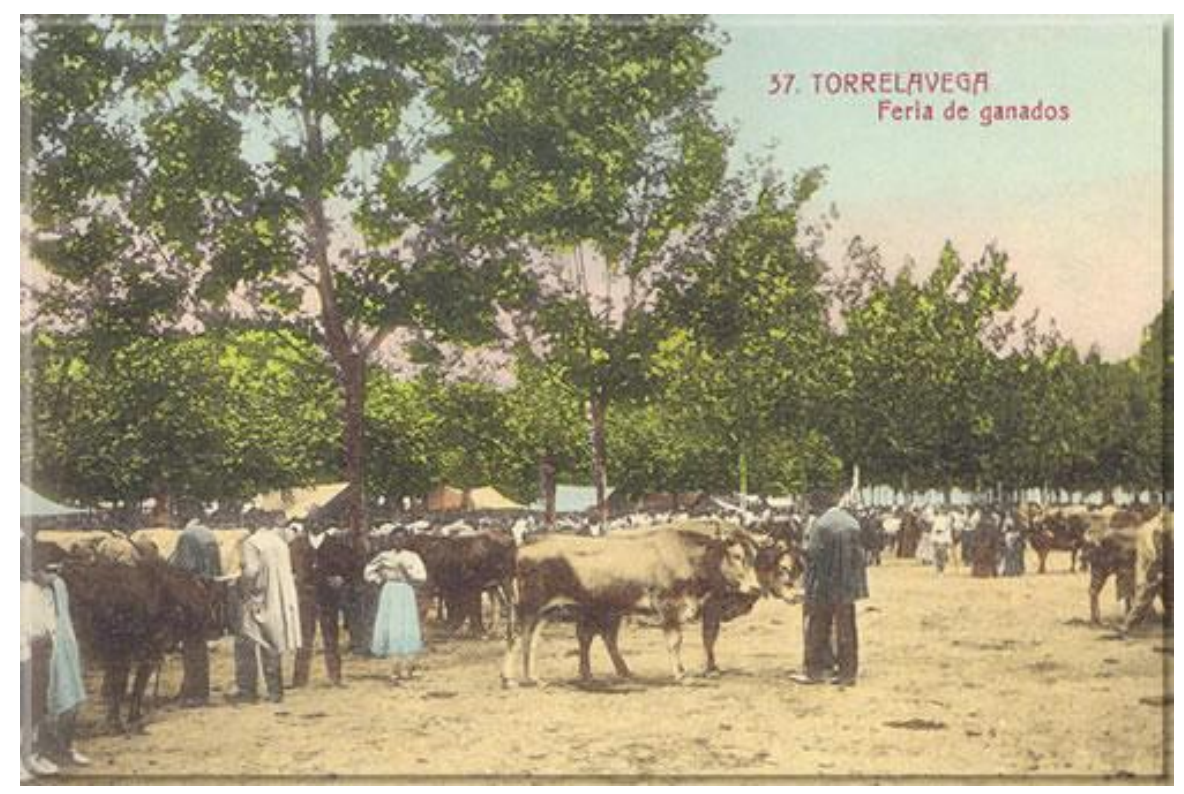

FuENTE: Colección de Ricardo Bueno, Torrelavega

Más tarde, desde la segunda mitad del siglo XX, el medio rural de Canta-

\footnotetext{
${ }^{17}$ Como el publicado por La Producción Montañesa el 26 de noviembre de 1903 (recogido por Gutiérrez, 2003:170-174).
} 
bria, como en el resto de España y Europa, habría de sufrir unas intensas transformaciones que se ponen de manifiesto, entre otros aspectos, en los desequilibrios territoriales que actualmente se mantienen entre espacios urbanos y rurales y dentro de estos últimos, entre unas áreas rurales y otras. Así, en los años 70' las ferias de ganado tradicionales celebradas en los pueblos de Cantabria eran cada vez más escasas y anecdóticas, como era también exigua su capacidad para congregar público asistente fuera del ámbito de la actividad estrictamente pecuaria. Además, debemos tener también en cuenta que en 1973 empieza a funcionar el Mercado Nacional de Ganados de Torrelavega, con una superficie total de $150.950 \mathrm{~m}^{2}$, apto para albergar hasta 7.500 reses. La generalización de las explotaciones intensivas y estabuladas, los modernos requerimientos de calidad y de control sanitario, así como la más fácil accesibilidad de dicho Mercado y sus buenas dotaciones fueron haciendo menos atractiva la organización y convocatoria de ferias que retomaran los usos rurales tradicionales en otros lugares de la región.

Por lo tanto, habría que esperar al relanzamiento de las razas autóctonas y a las políticas europeas de conservación de la diversidad ganadera para ver resurgir el interés general por este tipo de manifestaciones.

\section{FERIAS, MERCADOS, EXPOSICIONES Y CONCURSOS DE GANADO EN LA ACTUALIDAD: UNA ACTIVIDAD RURAL TRADICIONAL CON CRECIENTE CAPACIDAD PARA ATRAER VISITANTES.}

Según la propia Consejería de Ganadería del Gobierno de Cantabria ${ }^{18}$, los concursos y exposiciones sirven para evidenciar los avances conseguidos tras la aplicación de los distintos programas de mejora ${ }^{19}$ y para estimular el espíritu competitivo de los expositores, al tiempo que constituyen una auténtica escuela de aprendizaje para ganaderos jóvenes.

Al explícito interés pecuario de estos acontecimientos, se añade hoy en día otro tipo de orientaciones mercantiles y festivas complementarias que, si bien como hemos visto en el apartado anterior pueden rastrearse desde antiguo en la región, en los últimos años han ido incrementando su peso, en re-

\footnotetext{
${ }^{18}$ En el preámbulo de la Orden DES/72/2009, de 23 de noviembre (BOC 4-12-2009), por la que se establecen las bases y la convocatoria 2010 de las ayudas a la celebración de ferias, concursos y exposiciones de ganado selecto bovino y demás especies animales.

${ }^{19}$ Esta mejora de la producción ganadera es además una de las misiones del Servicio de Producción Animal de la Dirección General de Ganadería, de la Comunidad Autónoma de Cantabria, tal y como se reconoce en su carta de servicios, actualizada a 3 de mayo de 2010 (BOC 18-5-2010).
} 
lación con la creciente funcionalidad turística y recreativa que recae sobre los espacios rurales.

Además, a esta orientación turística de las ferias ganaderas se suman fines sociopolíticos que buscan, en la pervivencia y el fomento de este tipo de actividades tradicionales, fundamentos ideológicos para ensalzar la conciencia y la identidad regional ${ }^{20}$.

En cierta forma podría decirse que, a medida que la ganadería merma su importancia en la Comunidad Autónoma como actividad económica y como sector productivo, las ferias de ganado van obteniendo otras funcionalidades distintas a las intrínsecamente ligadas a la actividad ganadera: esto es lúdicofestivas, patrimoniales, identitarias e ideológicas.

En este sentido, debido al mantenimiento de la tradición y al impulso moderno otorgando por instituciones públicas de ámbito regional y municipal, juntas vecinales y asociaciones de ganaderos, existe actualmente en Cantabria una multiplicidad de eventos de este tipo, sorprendente a simple vista por su disposición para generar flujos de visitantes y espectadores y que, principalmente centrados en el ganado bovino, se hallan incluidos en el calendario oficial de mercados, ferias, exposiciones y concursos de ganado de la Comunidad Autónoma.

Dentro de ellos cabe diferenciar las ferias de ganado selecto, los concursos monográficos regionales, los concursos y exposiciones comarcales, municipales o locales, las concentraciones de ganado y las pruebas de arrastre de especie bovina o equina. Asimismo, algunos de estos concursos se refieren específicamente a las razas autóctonas regionales, destacando sobre manera en este último caso el ganado tudanco ${ }^{21}$.

Más en concreto, en la actualidad se desarrollan en Cantabria cuatro concursos ganaderos de ámbito nacional, de los cuales dos tienen como lugar de celebración el Mercado Nacional de Ganados de Torrelavega: uno de ellos en el mes de marzo sobre bovino frisón y el otro en el de julio sobre caballos

\footnotetext{
${ }^{20}$ En las últimas décadas, en los distintos Gobiernos regionales de la coalición PSOE-PRC (Partido Regionalista de Cantabria) mantenida durante dos legislaturas, los Consejeros de Ganadería han sido integrantes de este último partido político: entre 1995 y 2003 José Álvarez Gancedo y desde entonces a marzo de 2011 Jesús Oria Díaz.

${ }^{21}$ De bello aspecto y claro porte montaraz, considerada "raza autóctona de protección especial" en el Catálogo Oficial de Razas de Ganado de España, actualizado por el Real Decreto 1682/1997 de 7 de noviembre (BOE 21-11-1997). Dicha catalogación se refiere a las razas de ganado autóctono español en grave regresión o en trance de desaparición.
} 
de pura raza española ${ }^{22}$. Además, también tienen carácter nacional el concurso de reses bovinas pardas de montaña que desde 2009 se lleva a cabo en el recinto ferial de Potes, en mayo y el más antiguo y popular de los cuatro: el de ganado tudanco en Cabezón de la Sal, también llamado "Olimpiada del tudanco" (fotos del GRÁFICO 4), que en octubre de 2011 ha alcanzado su XXXIII edición.

Gráfico 4. Concurso Nacional de ganado vacuno autóctono de raza tudanca (12-10-2009), Cabezón de la Sal: a la izquierda, concentración de reses y de público en la campa de Ontoria; a la derecha, "pasá" o pasacalles de reses y ganaderos ante el consistorio municipal contemplada por el público asistente.
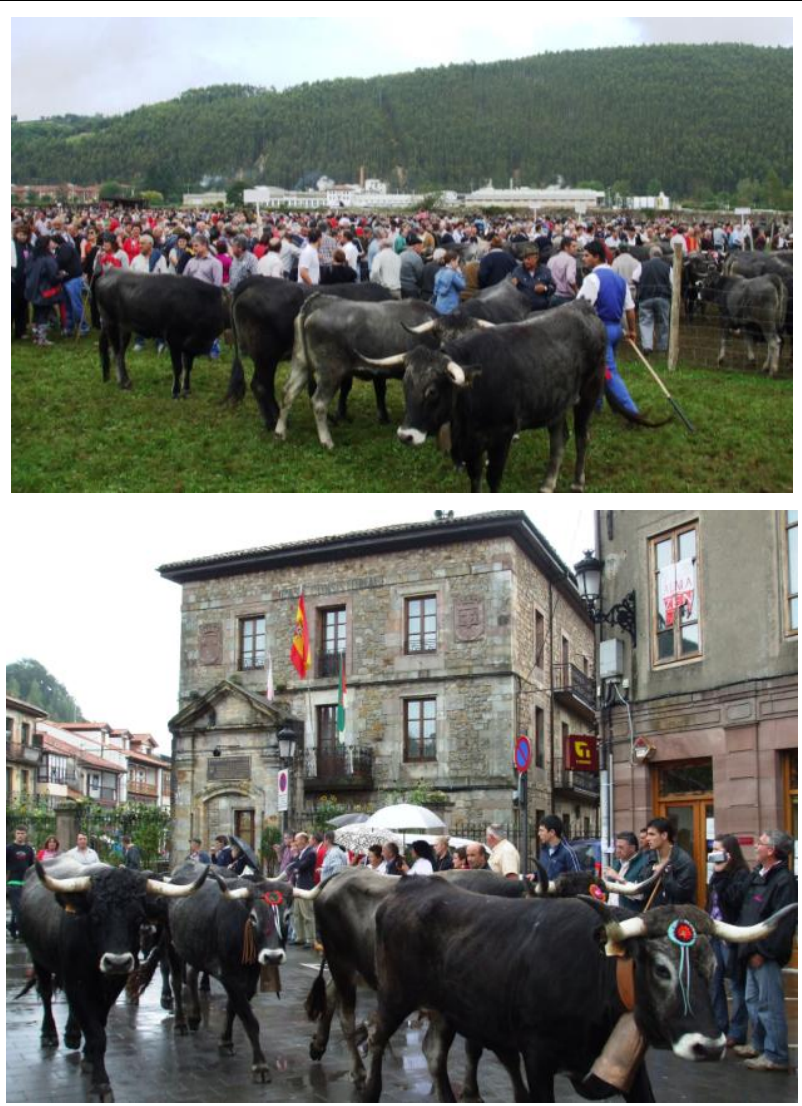

FUENTE: Fotos de la autora

${ }^{22}$ El primero de los citados, organizado por la Confederación de Asociaciones de Frisona Española (CONAFE), ha alcanzado en 2011 su XIII celebración y el segundo, concurso morfológico de caballos de pura raza española, su XX edición. 
Mapa 4. Cantabria: municipios en los que anualmente se celebran exposiciones y concursos de ganado bovino (incluyendo todas las especies y razas), 2011.

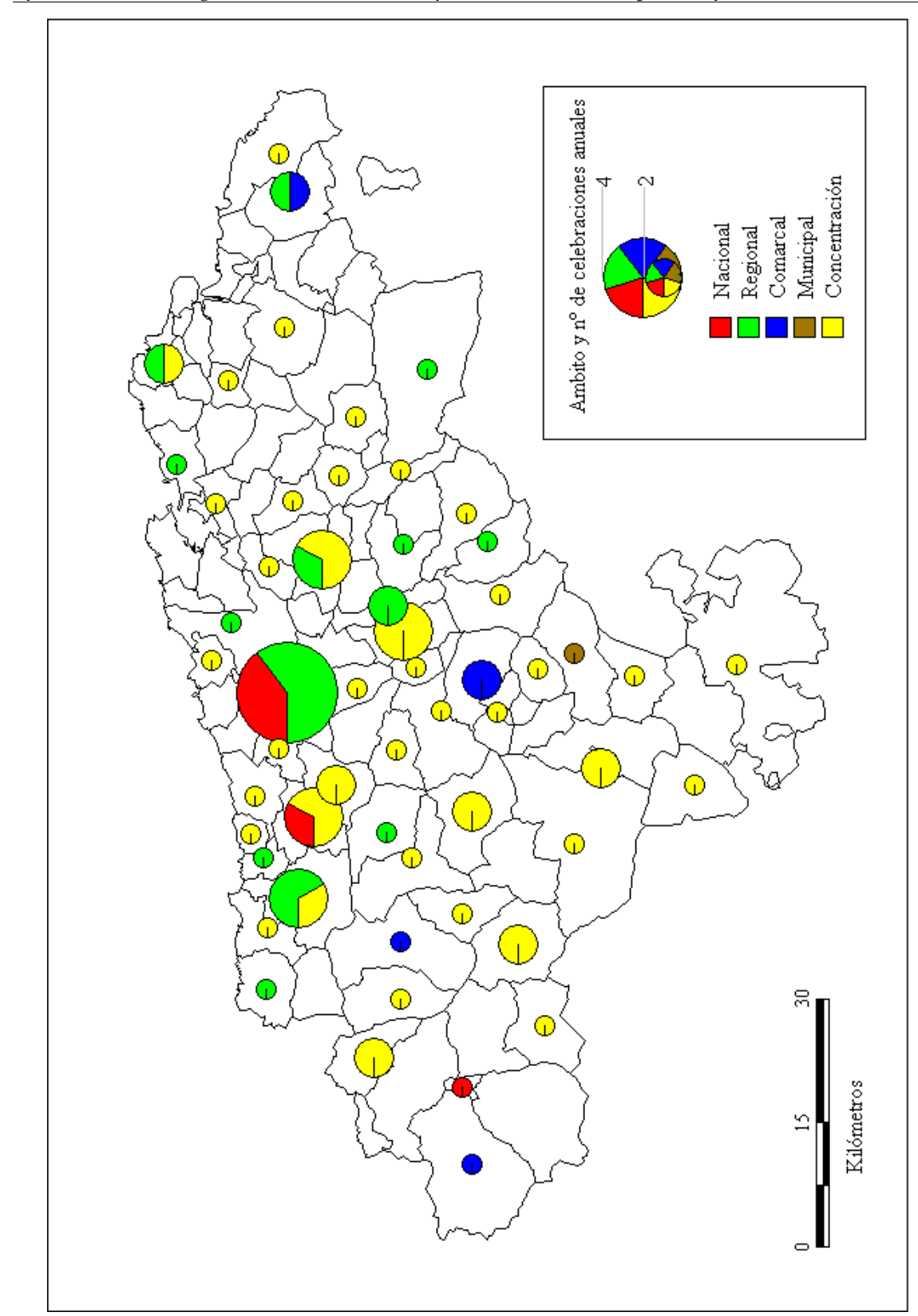

FuENTE: Calendario oficial 2011 de la Consejería de Desarrollo Rural, Ganadería, Pesca y Biodiversidad del Gobierno de Cantabria; elaboración propia 
El resto de exposiciones, concursos y concentraciones periódicas llegan a sobrepasar la cifra de setenta celebraciones anuales. En su mayoría, como ya hemos señalado, se refieren a ganado bovino, dada la orientación productiva regional, si bien en menor medida también hay muestras de equino y en ocasiones de ovino y caprino combinadas con las anteriores. Todas ellas se encuentran repartidas en distintas fechas y por diversos municipios de la región, alcanzando un carácter regional, comarcal o incluso municipal. Así, un total de cincuenta y siete municipios cántabros cuentan hoy en día con alguna celebración ganadera a lo largo del año ${ }^{23}$, si bien son cinco los más destacados (véase MAPA 4).

A la cabeza por cifra de celebraciones se halla Torrelavega, donde en su Mercado Nacional de Ganados, además de los dos concursos nacionales a los que ya nos hemos referido, se desarrollan otros tres de carácter regional en abril, mayo y septiembre ${ }^{24}$.

Un puesto también apreciable es el de Cabezón de la Sal. En este municipio que da nombre a su propia comarca ganadera, además del Concurso Nacional de Ganado tudanco se producen dos concentraciones más: en la localidad de Casar de Periedo en el mes de noviembre para todas las especies vacunas y en la de Santibáñez en diciembre, por Santa Lucía, para bovino y equino.

Asimismo sobresale el municipio de Santa María de Cayón, con una concentración en el lugar de Abadilla en enero y otra en Lloreda a finales de agosto, ambas para todo tipo de razas bovinas además de algunos ejemplares de equino, ovino y caprino. A la par, en la localidad de Sarón se desarrolla un concurso específico de ámbito regional para raza frisona en el mes de septiembre.

Un caso similar es el de Corvera de Toranzo, con tres concentraciones anuales convocadas para todas las especies y razas: en Castillo Pedroso a finales de agosto, en el Parque de Alceda a finales de septiembre y en Villegar a finales de octubre.

\footnotetext{
${ }^{23}$ Incluidos dentro de la categoría de rurales, según el ya mencionado Decreto 30/2010 de 22 de abril, salvo los casos de Torrelavega y Piélagos que por sus características y tamaño de población pueden considerarse claramente urbanos.

${ }^{24}$ El de abril referido a vacadas de raza limusina, el de junio para vacas, crías y sementales de razas asturianas de los valles y de la montaña y el de septiembre nuevamente para raza frisona.
} 
Por último es también notable el ejemplo de Valdáliga, donde en la localidad de Treceño tienen lugar una concentración de razas cárnicas en junio y dos concursos-exposiciones de ámbito regional muy consolidados: el uno para bovino frisón, igualmente en junio y el otro para bovino tudanco en noviembre $^{25}$.

En los demás municipios se dan entre una y dos concentraciones anuales. Dentro de este abundante conjunto de ferias, paradójicamente, las transacciones comerciales de ganado, aunque por lógica siguen existiendo, están dejando de ser lo más destacado. De esta manera, frente a la a menudo escasa cuantía alcanzada por las ventas, lo que predomina y lo que logra captar un volumen considerable de personas asistentes es el espectáculo de exhibición de animales limpios, lustrosos y engalanados que forman parte de las distintas cabañas ganaderas de la región. Desde el punto de vista antropológico podría decirse que se trata de escenificaciones de los usos rurales típicos y ancestrales vinculados al ámbito pecuario, que atraen al gran público y que se ven convertidos en componente patrimonial y en recurso turístico.

En esta línea, como contrapeso al esfuerzo efectuado por los ganaderos expositores es habitual la concesión de premios, así como la asignación de primas por cada animal desplazado, dotado de la correspondiente tarjeta sanitaria. Pese a estos incentivos y ayudas que tratan de fomentar estas prácticas y de compensar la falta de oportunidades de venta, en varias concentraciones resulta habitual que más copioso que el número de reses sea el de personas congregadas: ganaderos, comerciantes, responsables de la organización, representantes políticos, corresponsales de los medios de información, vecinos, espectadores y visitantes en general, venidos de la región y de otras provincias próximas.

\section{IV.1. Las ferias de año y el ciclo otoñal de celebraciones ganaderas.}

En ciertas localidades se mantienen de forma arraigada diversas ferias de año, usualmente coincidiendo con festividades religiosas. Así por ejemplo, en la zona occidental de Cantabria se celebra una feria de estas características en Ruente, en marzo, coincidiendo con San José y otra en Reinosa por Santiago, a finales de julio. Por su parte en la Marina Oriental, en la localidad de Hoznayo dentro del municipio de Entrambasaguas, la festividad elegida para la feria de año es San Lucas en octubre.

\footnotetext{
${ }^{25}$ El concurso-exposición de junio ha llegado en 2011 a su XXIV edición y el de noviembre a la XXX.
} 
De estas ferias de año existen varias en Potes, cabecera comarcal de Liébana, en los meses de enero, marzo, mayo y junio, esta última por San Pedro. Sin embargo la más conocida y frecuentada es la que coincide con la festividad de Todos los Santos. En ella participan reses equinas y vacuno de razas cárnicas. En sus últimas celebraciones, la presencia de ganado ha sido muy abundante, superándose en cada ocasión las dos mil cabezas. Aparte de los ganaderos expositores procedentes de este sector occidental de Cantabria, acude también numeroso público visitante, procedente no sólo del conjunto de la región sino también de Castilla y León y de Asturias, llegando a abarrotar las calles de la localidad y creando una notable animación, para contemplar el llamativo espectáculo de la "pasá" que discurre por las calles de la villa, como año tras año se recoge en distintos artículos de prensa de tirada regional (así por ejemplo el GRÁFICO 5).

También el municipio de Arrendondo, en la cabecera del río Asón, esta vez en la Montaña Oriental de Cantabria, celebra su feria anual coincidiendo con la conmemoración de Todos los Santos. Ésta tiene como peculiaridad el ser considerada uno de los más importantes encuentros ganaderos de ovejas y cabras de toda la cornisa cantábrica. Como suele ser habitual en otros casos, la feria ganadera de Arredondo se desarrolla acompañada de un mercado ambulante, que en 2010 llegó a distribuir por toda la localidad cerca de doscientos puestos para la venta de productos de la zona, lo que constituye un substancial atractivo para los comerciantes del área y para el público asistente. De tal manera, durante las últimas celebraciones, la feria que concluye con una romería o festejo popular ha llegado a contabilizar varios miles de visitantes de procedencia diversa.

Además, las actividades de la feria de Arredondo aparecen combinadas con otras ofertas de ocio, como las marchas excursionistas de subida a Porracolina $(1.414 \mathrm{~m}$.) siguiendo una de las rutas senderistas más repetidas de la región, clasificada como sendero de pequeño recorrido. Otra posibilidad es la visita al centro de reproducción de salmones situado en la misma localidad de Arredondo o al centro de interpretación de este espacio de montaña gestionado por la Fundación Naturaleza y Hombre ${ }^{26}$.

Como puede verse, por períodos o meses, destaca el número de manifestaciones de septiembre, octubre y noviembre, ciclo otoñal en el que se agrupa

\footnotetext{
${ }^{26}$ Así como la de adentrarse en los sistemas subterráneos de cuevas y cavidades cársticas con más de doscientas cincuenta cavidades catalogadas, como la de Cueto-Coventosa. Todas estas propuestas y actuaciones de fomento de la actividad turística en esta zona han sido apoyadas por el Plan de Dinamización Turística puesto en marca hace una década en los municipios que forman parte de la cabecera alta del Asón.
} 
prácticamente la mitad de todos los certámenes de la región y en especial los que conservan un sentido más tradicional o folklórico, coincidiendo su inicio con la bajada del ganado desde los pastos o brañas en los puertos de altura hacia los valles, para pasar los meses más fríos y húmedos, de otoño e invierno. Son además estas celebraciones las que más se resaltan en la prensa regional y en este sentido, capaces de emplazar las mayores afluencias de público no ganadero.

Gráfico 5. La repercusión mediática: la feria de Todos los Santos, en el municipio de Potes, contada por la prensa de la región.

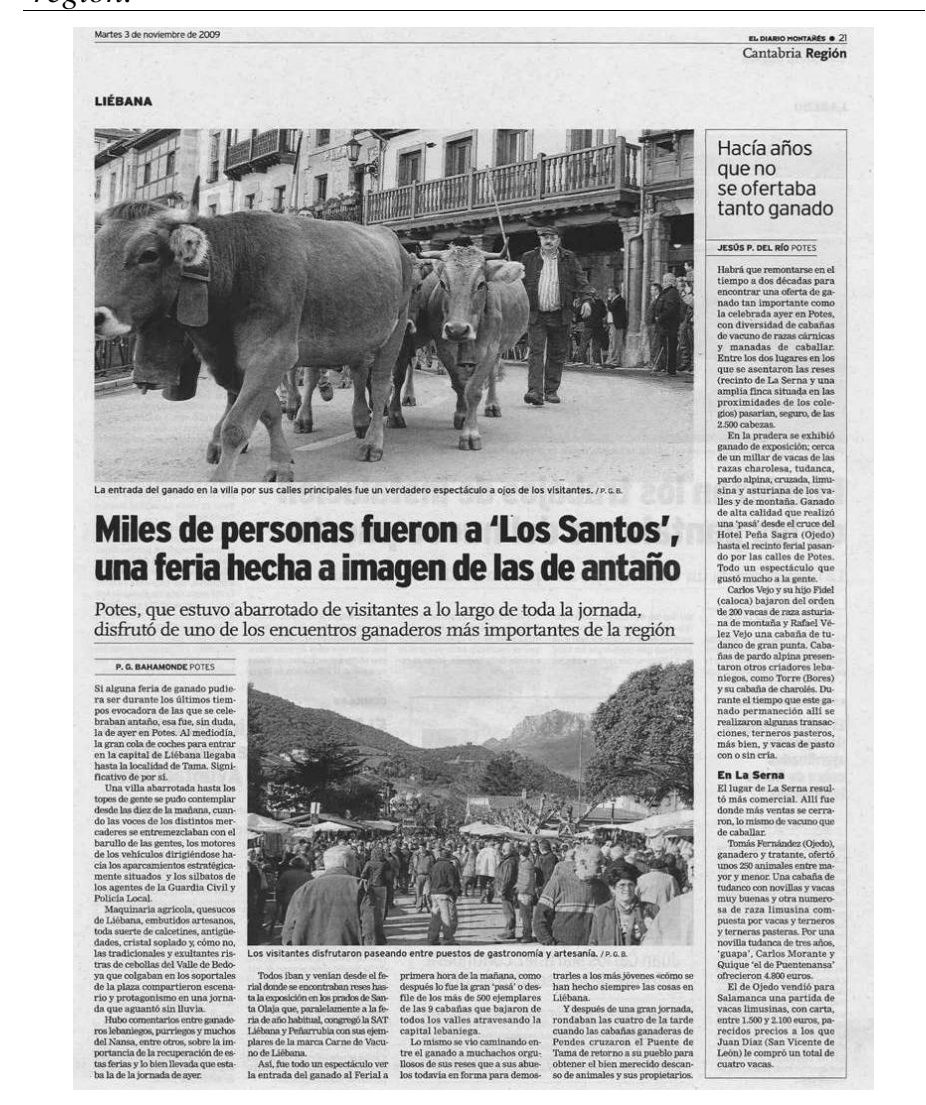

FUENTE: El Diario Montañés, 3 de noviembre de 2009

Uno de los casos más representativos es la Fiesta de los Campanos de Abiada, celebrada el primer domingo de septiembre en el municipio de la Hermandad de Campoo de Suso, para conmemorar la antigua tradición de 
descenso del ganado al final del estío desde las zonas de pasto de montaña hacia los pueblos. En ella las reses tudancas son engalanadas con adornos florales y grandes campanos con su tañido característico que dan nombre a la celebración. De este modo se lleva a cabo la popular "pasá" amenizada por piteros y pandereteros y en la que también participan mozos y mozas vestidos con trajes típicos campurrianos. Los orígenes del desfile, desde las brañas comunales en las faldas de la Sierra del Cordel hasta el pueblo de Abiada, se remontan a mediados del siglo XIX. En 1962 fue declarada fiesta de interés turístico, siéndolo actualmente de carácter regional. Las últimas celebraciones han llegado a congregar más de mil personas de fuera del municipio, con actividades asociadas como la realización de festivales de música popular.

De hecho, como puede deducirse de lo ya señalado hasta ahora, en los últimos años, este tipo de desfiles de exhibición o paso de ganado tudanco por las calles principales de algunos pueblos de Cantabria, conocidos con el nombre de "pasá", se han hecho cada vez más multitudinarios en lo que a afluencia de público se refiere. Así por ejemplo, con una presencia masiva de visitantes, concluyen los Concursos Nacionales de ganado vacuno de raza tudanca celebrados por la festividad del Pilar en Cabezón de la Sal, a los que ya hemos hecho referencia -recuérdese el GRÁFICO 4-.

Una prueba más de este auge generalizado de las "pasás" de ganado tudanco son las que recientemente, a partir de 2010, han empezado a celebrarse en la villa de Comillas a principios de septiembre, con la participación de ganaderos de la zona occidental de la región cuyo objetivo esencial es mostrar su cabaña de reses. Al final del recorrido, los animales acaban concentrándose en la campa de Sobrellano, a los pies del Palacio del Marqués y muy cerca del edificio de la Universidad Pontificia, por lo que dicho recorrido resulta un atractivo turístico más, ya a finales de la temporada veraniega.

Otras concentraciones pertenecientes también al ciclo otoñal son la de Puente Pumar en Polaciones y la del Prado Socollo en Rionansa, así como la de Molledo y la de San Miguel de Aguayo o la de Vega de Pas, todas ellas convocadas en el mes de septiembre.

Por su parte, entrado el mes de octubre se acrecienta considerablemente el número de celebraciones. Así en Campoo-Iguña destacan la de Cotillo de Anievas y la de Requejo en Campoo de Enmedio. En el mismo mes se celebran la de Merilla en San Roque de Ríomiera y la de Las Hayas en Liérganes, esta vez en el sector oriental. Además, en la Montaña Occidental tienen lugar, entre otras, la de Correpoco en Los Tojos, la del campo ferial de La Lastra en Tudanca, la de Vega de Camaleño, la de Lerones en Peseguero, la 
del Collado de Hoz en Peñarrubia y el concurso exposición de ganado tudanco en Ruente. Aunque posiblemente las más singulares y conocidas sean las que se desarrollan en las localidades de Carmona y Valle, en el municipio de Cabuérniga. Esta última localidad, situada en el curso medio del río Saja, es capital del municipio y tiene también conexión con la cuenca del Nansa, al que pertenece el núcleo de Carmona, declarado Bien de Interés Cultural en 1985 en la categoría de Conjunto Histórico. En dicho núcleo, el último sábado de septiembre, tiene lugar una frecuentada "pasá" de rebaños de raza tudanca que fue recuperada con fines turísticos a comienzos de la década de 1990. Por su parte, la feria de Valle de Cabuérniga se lleva a cabo a finales del mes de octubre, tras la bajada definitiva de las cabañas bovinas de los puertos de Sejos donde habitualmente pasan el verano, en pleno corazón del Parque Natural Saja-Besaya. Como ya hemos indicado, entre las especies participantes predomina claramente la raza tudanca, característica de esta comarca con una fuerte tradición ganadera de explotaciones extensivas en zonas de pastos. En los últimos años la feria de Valle, estimada como una de las más antiguas y emblemáticas de la región, está recibiendo una considerable atención por parte de los medios de comunicación regionales, en especial de la prensa escrita -GRÁFICO 6-, pero también de algunas cadenas de televisión de ámbito autonómico que establecen programaciones especiales. Todas estas circunstancias vienen contribuyendo a incrementar la presencia de visitantes que pasan la jornada festiva en el municipio y que retornan de unos años a otros.

Finalmente, para rematar el año, entre noviembre y diciembre, se realizan concentraciones de bovino en Quintanilla de Lamasón, en Villayuso de Cieza, en Silió municipio de Molledo, en San Felices de Buelna, en Ibio en Mazcuerras y en Arenas de Iguña.

La celebración de este último municipio, que se repite sin interrupción desde 1980, acontece el segundo domingo de noviembre en la finca de la Marquesa de Santa Cruz, contigua a la Casona y al Palacio de los Hornillos en las Fraguas, cedida anualmente a tal efecto ${ }^{27}$. Dicho entorno arquitectónico y paisajístico resulta enormemente atractivo, no en vano está considerada como una de las fiestas más representativas del municipio y de toda la comarca de Iguña, con una dotación destacada en premios ${ }^{28}$. En cuanto a vacuno prevalecen las razas cárnicas, aunque como sucede en otras ferias tam-

\footnotetext{
${ }^{27}$ La Casona fue construida a finales del siglo XVIII mientras que el Palacio, de estilo inglés, se construyó entre finales del XIX e inicios del XX y sirvió de inspiración al posterior Palacio de la Magdalena en Santander.

${ }^{28}$ En cada una de las últimas ediciones, entre 2008 y 2010, el ayuntamiento ha otorgado más de 6.000 euros en premios a los ganaderos participantes.
} 
bién participan ganado caballar y algunos rebaños de ovejas y cabras. Además de la notable aglomeración de público que acude todos los años a presenciar las actividades, destaca asimismo la abundancia de puestos de venta que ocupan las proximidades de la pradería en la que se produce la concentración. Junto con la feria de ganado, resultan igualmente concurridos los concursos de arrastre a cargo de parejas de bueyes que vienen efectuándose la víspera de la celebración, proponiéndose así un completo fin de semana festivo en el municipio -GRÁFICO 7-.

Gráfico 6. La creciente atención informativa y promocional: artículo en la prensa regional sobre las ferias ganaderas de Valle de Cabuérniga y Ruente.

\section{CABUÉRNIGA \\ La feria ganadera de Valle atraerá mañana a cientos de visitantes}

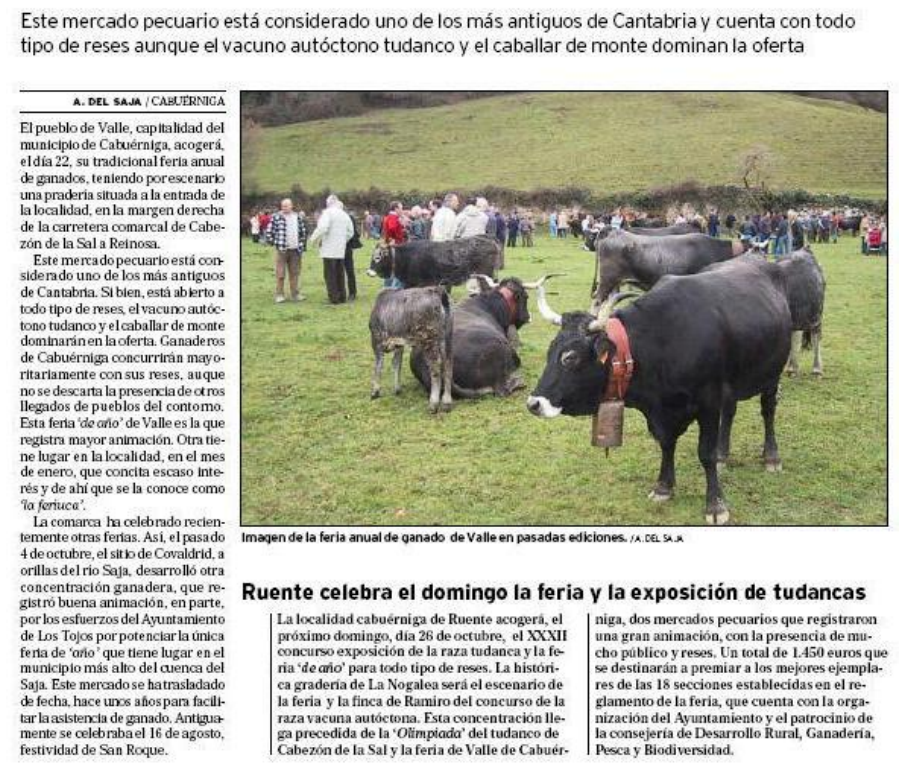

FUENTE: Alerta, 21 de octubre de 2008.

Así hay que precisar que desde hace ya algunos años, la celebración de ferias pecuarias ha venido sirviendo de marco para la presentación de proyectos de promoción turística y cultural en varios de los municipios rurales de interior. Una muestra de ello es el museo etnográfico José María de Cos, dedicado a la actividad agrícola, silvícola y ganadera. Su inauguración en Valle de Cabuérniga como parte del Ecomuseo Saja-Nansa se produjo en octubre 
de 2008, coincidiendo precisamente con la feria de año del municipio. Los responsables de llevarla a cabo fueron el entonces Presidente regional de Cantabria y el Consejero del ramo. Ambos, en declaraciones recogidas en prensa, consideraron dicho proyecto museístico como "auténtico paradigma de la identidad cántabra". La obra, encuadrada dentro del programa de desarrollo rural Leader Plus Saja-Nansa, permitió la recuperación de una antigua casona montañesa ${ }^{29}$.

\section{IV.2. Una propuesta de museo ganadero: el centro de interpretación de las ferias en Torrelavega.}

Otra prueba de este proceso de patriminolización de las ferias ganaderas y de su utilización como recurso turístico es el proyecto no materializado, pero hecho público a finales de marzo de 2011 por la Consejería de Desarrollo Rural, Ganadería, Pesca y Biodiversidad del Gobierno Regional y el Ayuntamiento de Torrelavega para la construcción de un centro de interpretación de las ferias ganaderas de Cantabria, en las dependencias del recinto ferial del Mercado Nacional de Ganados de Torrelavega, con un presupuesto inicial de quinientos sesenta y cinco mil euros, a realizar a través de una empresa pública ${ }^{30}$.

En la presentación de dicho proyecto, el que fuera Consejero de Ganadería hizo explícitos los dos objetivos del mismo: por una parte, rendir homenaje al sector de la ganadería en Cantabria y por otra, proponer un nuevo recurso turístico para la comarca de Torrelavega, favoreciendo el tejido comercial del área urbana de Nueva Ciudad, donde se halla emplazado el ferial.

De esta manera, el proyecto de museo ganadero aparecía concebido como un complemento del propio Mercado Nacional de Ganados. Este último, además de ser en la actualidad el equipamiento público más conocido y visitado del municipio ${ }^{31}$, es considerado por las Administraciones municipal y

\footnotetext{
${ }^{29}$ Supuso una inversión superior a los 550.000 euros para restaurar el edificio de tres alturas: una planta baja con un salón de actos y un punto de información, y otras dos plantas orientadas a la realización de exposiciones que den a conocer a los visitantes las tradiciones etnográficas y el patrimonio cultural y natural de la zona.

${ }^{30}$ El grupo empresarial de capital público Tragsa, especializado en la conservación de la naturaleza, el desarrollo rural y la prestación de servicios de emergencia, creado en 1977 a partir del Parque de Maquinaria del Instituto Nacional de Reforma y Desarrollo Agrario (IRYDA).

${ }^{31}$ Estimado como uno de los más importantes de España, todos los miércoles del año, se celebran en el Mercado de Ganados de Torrelavega citas pecuarias de ganado saneado vacuno, equino, asnal, ovino y caprino. Además, como ya hemos señalado, a estas más de cincuenta ferias regulares anuales se suman otras ferias, concursos y exposiciones puntuales.
} 
autonómica como uno de los principales atractivos para la promoción turística y terciaria de Torrelavega.

Gráfico 7. Feria de ganado en Arenas de Iguña: concurso de arrastre durante la jornada previa y entrada de las reses en la finca, observada por numeroso público.
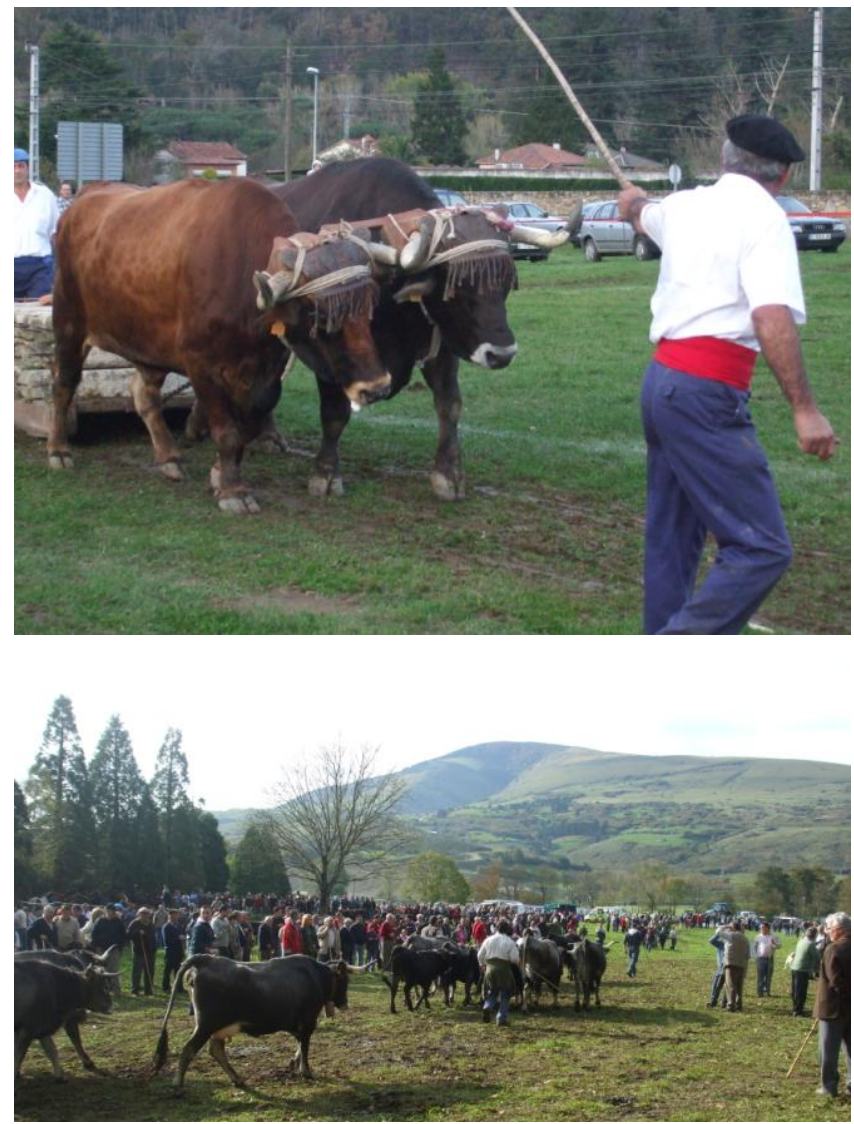

FUENTE: Fotos de la autora

El proyecto elaborado para el diseño del centro de interpretación de las ferias y mercados ganaderos se articulaba como un trayecto a lo largo de ocho grandes áreas temáticas, distribuidas en mil seiscientos metros cuadrados situados en la primera planta del recinto ferial. El enfoque planteado pretendía 
tener un carácter predominantemente didáctico ${ }^{32}$, a partir de varias secuencias de paneles informativos con textos, gráficos e imágenes y el uso de recursos audiovisuales, nuevas tecnologías y dispositivos interactivos.

De esta manera se abarcarían de forma contextualizada y amena los diferentes aspectos relacionados con el sector ganadero: la estabulación, la subida a los puertos, los tratos y mercados ganaderos, la atención veterinaria, los útiles y la artesanía asociada a las ferias, etc.

No obstante, tras las elecciones autonómicas de 2011, dicho proyecto, para cuyas labores de ejecución se preveía un comienzo inminente al término de la pasada legislatura, fue descartado por los nuevos responsables de la Consejería, tras someterlo a un estudio de viabilidad y considerarlo un coste excesivo y poco justificado desde el punto de vista estrictamente ganadero. Todo ello también pese a la insistencia a favor por parte del pleno municipal del Ayuntamiento de Torrelavega.

Por el contrario, entre los nuevos proyectos del actual ejecutivo se encuentra la posibilidad de incrementar los usos del recinto ferial de Torrelavega, potenciando las ferias semanales, ampliando el calendario de ferias anuales y dando entrada a un mercado agroalimentario en el que se promocionan productos de la región. Evidentemente las circunstancias económicas actuales no parecen favorables para crear nuevos museos etnográficos y centros de interpretación de una utilidad incierta para el propio sector pecuario, pero la presentación del proyecto no deja de ser una muestra palpable de los procesos de patrimonialización y de turistificación que afectan hoy en día a las ferias.

\section{ALGUNAS CONCLUSIONES Y VARIOS INTERROGANTES.}

A lo largo de este artículo, hemos puesto de manifiesto la orientación turística que, como prácticas singulares apoyadas en la tradición popular y en nuevos valores culturales, están adquiriendo las ferias de ganado en Cantabria. Ello explica la relevancia que este tipo de festejos sigue teniendo en las zonas rurales de la región, así como su incremento a lo largo de los últimos años. En efecto, estas celebraciones periódicas constituyen hoy en día un interesante complemento a las actividades de turismo rural, que hasta ahora han estado casi exclusivamente centradas en la oferta de alojamientos ${ }^{33}$ (GIL,

\footnotetext{
${ }^{32}$ Teniendo en cuenta que son frecuentes las visitas al Ferial de Ganados de Torrelavega por parte de escolares de la región.

${ }^{33}$ Regulados por el Decreto 31/1997 que establece los requisitos que deben cumplir los establecimientos de turismo rural de la región en sus diferentes categorías: palacios y casonas, posadas, casas de labranza y viviendas rurales.
} 
2006), sin contar en numerosas ocasiones con un volumen suficiente de actividades complementarias.

Así, dentro de esta creciente funcionalidad turística y de ocio atribuida a los espacios rurales en el contexto socioeconómico global de los países occidentales, las ferias tradicionales de ganado convertidas en recurso turístico, fácilmente identificables por la potencial demanda y capaces de consolidar una imagen de marca para el turismo de interior en Cantabria, contribuyen a crear un sello distintivo de los espacios rurales de la región, entroncando con su pasado histórico y diferenciando su oferta de la de otros destinos.

En relación con este orientación turística y recreativa se encuentra también su puesta en valor como recurso cultural, lo que nos permite hablar de un incipiente proceso de patrimonialización de las ferias ganaderas, en el que intervienen factores y agentes externos: desde la propia Administración regional a través de su Consejería de Ganadería, hasta los medios de comunicación, comerciantes y visitantes urbanos.

En tercer lugar, desde el punto de vista de cómo son percibidas este conjunto de celebraciones ganaderas por parte de la población de Cantabria, su apogeo actual favorece la recreación y la reinvención de un pasado secular y por ende sirve de acicate para reforzar la identidad regional, legitimando así no sólo determinadas interpretaciones de la realidad relativa a sus espacios rurales, sino también la puesta en marcha de diversos proyectos auspiciados por las instituciones regionales y locales y relacionados con el desarrollo territorial y la integración socioeconómica de estos espacios.

Pero además de establecer estas conclusiones apoyadas en lo analizado en este artículo, cabe también, para cerrar este trabajo y para plantar una posible línea de investigación futura, esbozar algunos interrogantes sobre los efectos derivados de la actividad turística rural, teniendo presentes los criterios de los propios ganaderos, a quienes, paradójicamente, por el momento no se les han dado suficientes oportunidades para exponer sus consideraciones con respecto a los cambios que hemos estudiado y que afectan a su actividad.

Así, con frecuencia, en lo que respecta al tratamiento que se da a este tipo de manifestaciones festivas en los medios de comunicación, los ganaderos aparecen como supuestamente orgullosos y satisfechos de poder mostrar al espectador foráneo, de dentro y fuera de la región, su ganado y de que el público urbano conozca y se interese por su trabajo, llevando a cabo para ello un considerable esfuerzo como colectivo, lo que además justifica la recepción de las ayudas y subvenciones otorgadas por parte de las Administraciones públicas. 
Sin embargo y puesto que los procesos de transformación analizados en este trabajo son relativamente recientes, de cara a un futuro a medio plazo y según las opiniones recabadas ente los propios ganaderos, cabe preguntarse si las ferias y la orientación turístico-recreativa que están tomando servirán como nuevo estímulo para potenciar las actividades agropecuarias, beneficiando en último término a las poblaciones rurales que, de unas generaciones a otras, han hecho de estas prácticas su oficio y su modo de vida o si por el contrario, estas poblaciones acabarán sirviendo tan sólo de meros figurantes, dentro de un proceso imparable y global de turistificación y terciarización de los espacios rurales.

Este otro escenario de evolución resulta bastante menos optimista de lo que hasta ahora trasciende en relación con las prácticas de turismo rural y acabaría afianzando una subordinación cada vez mayor a intereses y demandas externas, y por lo tanto mermando la capacidad de los habitantes de estas zonas rurales para tomar iniciativas y para gestionar sus propios recursos y territorios.

\section{BIBLIOGRAFÍA}

AZCUÉNAGA VIERNA, J. (2009-2010): «Ferias y exposiciones de ganado en Cantabria en la primera mitad del siglo XIX (Primera parte)», Anales del Instituto de Estudios Agropecuarios, nº 19, 15-176.

BARRÓN GARCÍA, J.I. (1995): «La economía de Cantabria en la etapa de la restauración (1875-1908)», Revista de Historia Económica-Journal of Iberian and Latin American Economic History, año 13, no 1, 160-164.

Casado Cimiano, P. (1983-84): «La más famosa de las primeras exposiciones de ganado: la celebrada en Santander en el año 1872», Anales del Instituto de Estudios Agropecuarios, vol. VI, 193-230.

CASAdo Cimiano, P. (1988): «El $20^{\circ}$ concurso de ganados y exposiciones de industrias lácteas celebrados en Santander en el año 1911», Anales del Instituto de Estudios Agropecuarios, vol. X, 117-142.

COLlANTES GuTiÉRREZ, F. (2003): «La ganadería de montaña en España 18652000: Historia de una ventaja comparativa anulada», Historia Agraria, $\mathrm{n}^{\mathbf{0}} 31$, 141-167.

CORBERA Millán, M. (2006): «Políticas públicas, territorio rural y sostenibilidad. Una visión desde el norte de España», Boletín de la Asociación de Geógrafos Españoles, $\mathrm{n}^{\circ}$ 41, 221-242.

CORBERA MiLláN, M. (2006): «Técnicas pastoriles y paisaje rural: origen y evolución de las praderías invernales en los valles de Nansa-Lamasón», Ería, Revista cuatrimestral de geografía. $\mathrm{n}^{\circ} 71,301-318$.

DELGADO ViÑAS, C. (1998): «Cambios recientes en las orientaciones productivas de la ganadería bovina en Cantabria», IX Coloquio de Geografía Rural: comunicaciones. 403-412. 
DELGADO ViÑAS, C. (2001): «La diversificación espacial de la ganadería bovina en Cantabria», F. MANERO MiguEL (coord.): Espacio natural y dinámicas territoriales: homenaje al Dr. Jesús García Fernández, Valladolid, Universidad de Valladolid, 409-422.

DELGADO ViÑAS, C. et AL. (2005): «Terciarización turística y difusión urbana en un espacio rural de montaña: la segunda residencia en el sector central de la Cordillera Cantábrica», en T.M. MAZón MARTíneZ y A. Aledo TuR (coords.): Turismo residencial y cambio social, nuevas perspectivas teóricas y empíricas. Alicante, Universidad de Alicante, 157-172.

Gil DE ARRIBA, C. (2002): Ciudad e imagen. Un estudio geográfico sobre las representaciones sociales del espacio urbano de Santander. Santander, Servicio de Publicaciones de la Universidad de Cantabria.

GIL DE ARRIBA, C. (2006): «Turismo y segunda residencia en la montaña cantábrica: expectativas y riesgos», ne C. DELGADO VIÑAS (coord.): La montaña cantábrica, una montaña viva. Santander, Universidad de Cantabria, Parlamento de Cantabria, 129-150.

Gómez Pellón, E. (2008): «Cambio y crisis en el medio rural de Cantabria», en Mazón Nieto De Cossío, J. J. (coord.): Vacuno de leche en Cantabria. Santander, Cantabria Tradicional. 29-52.

GuTIÉRREZ FERNÁNDEZ J.M. (2003): Las ferias anuales de ganado en Cantabria, Santander, Cantabria Tradicional.

LANZA GARCÍA, R. (2001): «El crecimiento de la ganadería de Cantabria entre los siglos XVI y XIX: una temprana especialización regional», Historia Agraria, ${ }^{\circ}$ 23, 79-118.

LE BouIL, J. (1965): «Sociétés économiques et juntes d'agriculture. Notes sur l'échec d'une révolution agricole à Santander au XIXe siècle», Mélanges de la Casa de Velázquez, vol. 1, nº 1, 323-343.

MAdARIAGA De LA CAMPA, B. (1970): «La ganadería en la provincia de Santander», Anales del Instituto de Etnografía y Folklore, vol. II, 173-210.

MADARIAGA DE LA CAMPA, B. (1981): «Bosquejo histórico sobre el desarrollo del ganado bovino en la Montaña», El Campo, 84, 47-50.

PAZ SÁEZ, A. (1988): «Aspectos antropológicos y sociales de las Ferias Ganaderas», Revista internacional de sociología, $\mathrm{n}^{\circ} 2,289-298$.

Perez Alvarez, M.J. (1997): «Las ferias de ganado vacuno en la ciudad de León», Investigaciones históricas: Época moderna y contemporánea, $\mathrm{n}^{\circ}$ 17, 43-60.

PUENTE FERNANDEZ, L. DE LA (1992): Transformaciones agrarias en Cantabria, 1860-1930 : especialización vacuna y construcción del espacio agrario. Santander, Universidad de Cantabria y Asamblea Regional de Cantabria.

Velasco Maíllo, H.M. (2004): «El mercado como sociedad. Roles y grupos en mercados y ferias de ganado en Castilla y León», Salamanca: revista de estudios, $\mathrm{n}^{\mathrm{o}} 51$ (ejemplar monográfico dedicado a la cultura de tradición oral. Homenaje a Ángel Carril), 193-216. 